\title{
Efeito modulador do óleo essencial do limão Taiti (Citrus latifolia) em células somáticas de Drosophila melanogaster
}

\author{
Modulating effect of essential oil of lemon Taiti (Citrus latifolia) on somatic cells of \\ Drosophila melanogaster
}

\author{
Bruna Cássia Silva ${ }^{1}$, Rosiane Gomes Silva Oliveira ${ }^{2 *}$, Mirley Alves Vasconcelos ${ }^{3}$ \\ ${ }^{1}$ Graduanda em Farmácia; Centro Universitário de Patos de Minas - UNIPAM; ${ }^{2}$ Doutora em Genética e Bioquímica; \\ Centro Universitário de Patos de Minas - UNIPAM; ${ }^{3}$ Mestre em Genética e Bioquímica; Centro Universitário de Patos \\ de Minas - UNIPAM.
}

\begin{abstract}
Resumo
Introdução: óleos essenciais são muito utilizados para fins terapêuticos e nas últimas décadas esse interesse tem aumentado exponencialmente devido aos avanços nas terapias naturais. Neste contexto, destaca-se o óleo essencial do limão Taiti, um produto com grande potencial terapêutico e farmacológico. Objetivo: este trabalho objetivou avaliar o efeito carcinogênico e anticarcinogênico do limão Taiti (Citrus latifolia), por meio do teste para detecção de clones de tumores epiteliais em células somáticas de Drosophila melanogaster. Metodologia: larvas de terceiro estágio, do cruzamento entre fêmeas virgens wts/TM3, Sb ${ }^{1}$ com machos $m w h / m w h$, foram tratadas cronicamente com diferentes concentrações do óleo essencial do limão Taiti $(1,5 ; 3,0 ; 6,0 \mu \mathrm{L})$ isoladamente e associadas à doxorrubicina (DXR), também foram incluídos dois controles, um negativo (Tween 80 1\%) e um positivo (DXR 0,4 mM). Resultados: os resultados revelaram que os indivíduos tratados apenas com as concentrações isoladas do óleo essencial do limão Taiti não apresentaram frequências significativas de tumores quando comparadas ao controle negativo $(p>0,05)$. Contudo, as concentrações associadas apresentaram efeito modulador sobre os danos induzidos pela DXR, pois houve redução significativa $(p<0,05)$ na frequência de tumores, quando comparadas ao controle positivo. Conclusão: o presente trabalho, em condição experimental, atesta que o óleo essencial de limão Taiti (Citrus latifolia) não apresenta ação carcinogênica e sim ação anticarcinogênica em Drosophila melanogaster. Palavras-chave: Antioxidante. Citrus. Neoplasias.
\end{abstract}

\begin{abstract}
Introduction: essential oils are widely used for therapeutic purposes and in recent decades this interest has increased exponentially due to advances in natural therapies. In this context, the essential oil of lemon Taiti stands out, a product with great therapeutic and pharmacological potential. Objective: this study aimed to evaluate the carcinogenic and anticarcinogenic effect of Tahiti lemon (Citrus latifolia) by testing for clones of epithelial tumors in Drosophila melanogaster somatic cells. Methodology: third stage larvae from crossbreeding wts / TM3, Sb1 virgin females with mwh / mwh males were chronically treated with different concentrations of Taiti lemon essential oil $(1.5 ; 3.0 ; 6.0 \mu \mathrm{L}$ ) alone and doxorubicin-associated (DXR), two controls were also included, one negative (Tween $801 \%)$ and one positive (0.4 mM DXR). Results: the results revealed that the individuals treated only with the isolated concentrations of Taiti lemon essential oil did not present significant tumor frequencies when compared to the negative control ( $p>0.05)$. However, the associated concentrations had a modulating effect on DXR-induced damage, since there was a significant reduction $(p<0.05)$ in the frequency of tumors when compared to the positive control. Conclusion: the present work, under experimental condition, attests that Taiti lemon essential oil (Citrus latifolia) did not show carcinogenic action but anticarcinogenic action in Drosophila melanogaster. Keywords: Antioxidant. Citrus. Neoplasias.
\end{abstract}

\section{INTRODUÇÃO}

O limão Taiti, é um fruto de origem tropical, de exploração econômica relativamente recente. No contexto mundial, os principais produtores são o México, Estados Unidos, Egito, Índia, Peru e Brasil. O Brasil se destaca como o segundo maior produtor de frutos cítricos e o maior exportador de sucos cítricos, tendo o limão Taiti

Correspondente/Corresponding: Rosiane Gomes Silva Oliveira - End; - E-mail - twl como um dos seus frutos de maior relevância comercial. (COELHO, 1993).

O peso do fruto do limão Taiti em média é de 170 $\mathrm{g}$, sendo a casca geralmente fina, com superfície lisa e cor amarelo pálido na etapa de maturação. É composta de duas frações distintas: o epicarpo e o mesocarpo, os quais são facilmente separáveis da polpa, que corresponde à fração comestivel do fruto. No epicarpo ou casca, encontram-se substâncias químicas como os carotenoides, vitaminas e óleo essencial (MENDONÇA et al., 2006).

As frutas cítricas possuem altas concentrações de óleo essencial presentes em glândulas localizadas na 
superfície da casca da fruta o qual podem ser removidos por diferentes métodos de extração, como hidrodestilação ou destilação por arraste de vapor, extração por solvente, prensagem a frio e extração supercrítica (FIGUEIREDO, 2010). É comum o uso deste óleo por indústrias de bebidas, refrigerantes, cosméticos, essências aromáticas, culinárias, entre outras (GRASSI FILHO et al., 2005).

Além da indústria, o óleo essencial das frutas cítricas tem sido utilizado para fins terapêuticos. $O$ crescimento do uso de terapias naturais no tratamento de várias doenças agudas e crônicas tem ocorrido de forma paralela ao progresso científico e tecnológico da medicina moderna ocidental, despertando, assim, o interesse de usuários, pesquisadores, profissionais e gestores de serviços de saúde (SPADACIO et al., 2010). As terapias naturais se configuram como opções para o cuidado à saúde, enquanto práticas terapêuticas, evidencia o amplo uso dessas terapias em alguns casos específicos como, por exemplo, para o câncer (SPADACIO; BARROS, 2008).

Silveira et al. (2008) confirmam que nas últimas décadas houve um aumento significativo do interesse pelas terapias naturais. Dentre os produtos naturais empregados em abordagens terapêuticas, o óleo essencial do limão Taiti, é descrito como produto com grande potencial terapêutico e farmacológico (EDRIS, 2007).

Como se trata de um composto muito utilizado pela população, o desenvolvimento de pesquisas que avaliem os seus efeitos moleculares é necessário. Neste caso ressalta-se, dentre outros, os possíveis efeitos na carcinogenicidade e anticarcinogenicidade, para tanto é relevante destacar o teste para detecção de clones de tumores epiteliais (ETT - Epithelial Tumor Test) em Drosophila melanogaster.

\section{MATERIAIS E MÉTODOS}

\section{AGENTES QUIIMICOS}

\section{Doxorrubicina (DXR)}

O cloridrato de doxorrubicina (DXR), um agente químico de ação citotóxica, foi utilizado neste estudo como controle positivo a uma concentração de $0,4 \mathrm{mM}$, preparada a partir da adição de 0,03538g de doxorrubicina em 25 $\mathrm{mL}$ de tween 80 a $1 \%$. Comercializado como Adriblastina RD, lote 5PL5111, CAS 25316-40-9, fabricado e embalado por Actavis Italy S. p. A. - Nerviano, Milão - Itália. Registrado, importado e distribuído por: Laboratórios Pfizer LTDA - Av. Presidente Tancredo de Almeida Neves, no 1555 - Guarulhos - SP.

Cada frasco-ampola contém 50mg de pó liofilizado para uso injetável. Seu uso é restrito a hospitais e a venda é feita sob prescrição médica. O produto deve ser armazenado em temperatura ambiente (entre $15 \mathrm{e}$ $30^{\circ} \mathrm{C}$ ), protegido da luz.

\section{Óleo essencial do limão Taiti}

Adquirido comercialmente, o óleo essencial da casca do limão Taiti foi produzido pela Phytotrata Cosmético Ltda. Guarulhos - SP, Rua Cavadas, 1744, CNPJ: 05.978.781/0001-07, lote POLT17.03, Reg. MS 2.03883-7. Res. Anvisa no 343/05. Responsável técnico: Mirian Porses Prates, CRQ-SP 04142888. O óleo foi diluído em Tween 80 a 1\% para obter as três concentrações 1,5; 3,0 e 6,0 $\mu \mathrm{L}$ usadas no experimento.

\section{Tween}

O Tween 80 ou polissorbato $80\left(\mathrm{C}_{64} \mathrm{H}_{12} 4 \mathrm{O}_{26}\right)$ é um surfactante não-iônico utilizado para emulsificar óleo em água (FENG et al., 2006), utilizado largamente em preparações farmacológicas, como aditivo alimentar e como emulsificante, estabilizador ou dispersante (DAHER; BAROODY; HOWLAND, 2003). Logo, o tween 80 foi utilizado neste estudo para diluir o óleo essencial do limão Taiti a uma concentração de $1 \%$.

\section{TESTES PARA DETECÇÃO DE CLONES DE TUMORES EPITELIAIS (ETT - Epithelial Tumor Test) EM Drosophila melanogaster}

\section{Linhagens estoque}

No teste para a deteç̧ão de clones de tumor epitelial (ETT) em D. melanogaster, foram utilizadas duas linhagens mutantes, a wts e a mwh, portadoras dos marcadores genéticos warts (wts, 3-100) e multiple wing hairs ( $m w h, 3$ $-0,3)$. As linhagens estoque são cultivadas no Laboratório de Citogenética e Mutagênese do Centro Universitário de Patos de Minas (UNIPAM), Patos de Minas-MG, em fras$\cos$ de $1 / 4$ de litro contendo meio de cultura próprio para D. melanogaster composto por $820 \mathrm{~mL}$ de água, $25 \mathrm{~g}$ de fermento biológico fresco (Sacchoromyces cerevisae), $11 \mathrm{~g}$ de ágar, $156 \mathrm{~g}$ de banana madura e $1 \mathrm{~g}$ de metilparabeno.

As condições propícias para manutenção das linhagens de $D$. melanogaster ocorrem por meio da conservação destas no interior de uma incubadora B.O.D. 411 D, em temperatura de, aproximadamente, $25^{\circ} \mathrm{C}$ e umidade em torno de $60 \%$.

\section{Cruzamentos e Tratamento}

Para a realização da pesquisa foi feito o cruzamento entre fêmeas virgens de wts/TM3, $S b^{1}$ com machos $m w h /$ mwh. A postura dos ovos descendentes deste cruzamento ocorreu por um período de 8 horas em frascos contendo meio próprio para postura, este meio contém ágar bacteriológico, água, banana nanica, nipagim e fermento biológico fresco. A coleta das larvas de terceiro de estágio, resultantes da eclosão dos ovos, ocorreu por meio de uma peneira de malha fina e água de osmose reversa.

Para o tratamento crônico, aproximadamente, 48 horas, as larvas de 3 o estágio foram transferidas para frascos de vidro, contendo 1,5g de purê de batatas umedecidos 
com $5 \mathrm{~mL}$ das diferentes concentrações do óleo essencial do $\operatorname{limão}$ Taiti $(1,5 ; 3,0 ; 6,0 \mu \mathrm{L})$, isoladas e associadas ao quimioterápico doxorrubicina (DXR 0,4 mM). Para controle positivo utilizou-se DXR 0,4 mM e para controle negativo o solvente Tween 80 a 1\% e água de osmose reversa.

\section{Análise das moscas}

Decorridos o período de metamorfose, procedeu-se com as coletas das moscas, as quais foram preservadas em etanol $\left(\mathrm{C}_{2} \mathrm{H}_{6} \mathrm{O}\right) 70 \%$ para posterior análise.

As moscas portadoras do genótipo wts $+/+m h w$, foram separadas e identificadas pela presença de pelos fenotipicamente selvagens (longos e finos). As moscas adultas que apresentarem pelos curtos e grossos foram descartadas, uma vez que não possuem o gene em estudo (TM3, Sb $\left.{ }^{1} / m w h\right)$.

A análise foi realizada com auxílio de lupa estereoscópica, placa escavada e glicerina $\left(\mathrm{C}_{3} \mathrm{H}_{8} \mathrm{O}_{3}\right)$ para permitir a contagem de tumores presentes no corpo da Drosophila. Os resultados foram tabulados em um diagrama padrão expressando os números de tumores encontrados em diferentes seguimentos, como cabeça, olhos, corpo, asas, pernas e halteres.

As diferenças estatísticas, entre a frequência de tumor das concentrações testadas e os controles (positivo e negativo), foram calculadas utilizando o teste $U$, não paramétrico, de Mann-Whitney, empregando o nível de significância $p<0,05$.

\section{RESULTADOS}

A presente pesquisa fez uso do teste ETT para avaliar o possível efeito carcinogênico e anticarcinogênico do óleo essencial do limão Taiti em Drosophila melanogaster. As larvas de terceiro estágio foram tratadas com diferentes concentrações do óleo essencial. Inicialmente foi realizada a separação dos indivíduos, levando em consideração o fenótipo. Os indivíduos adultos portadores de pelos longos e finos foram analisados quanto a presença de tumor, visto que estes são detentores do gene wts, já os indivíduos com pelos curtos e grossos foram descartados (Figura 1).

Figura 1 - (A) Mosca com pelos curtos e grossos - descartadas; (B) Mosca de pelos longos e finos com presença de tumor no tórax.

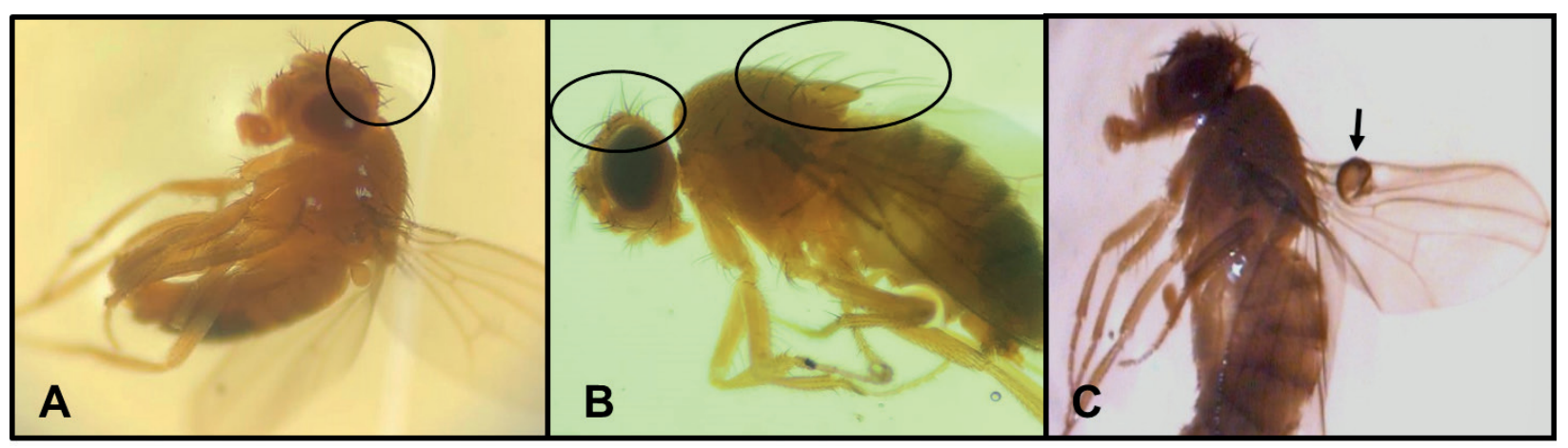

Fonte: Arquivo pessoal. 28 set. 2017.

Após a separação das moscas levando em consideração o fenótipo, foi realizada a análise individual de cada indivíduo, para quantificar o número de tumores.
Foram analisadas 150 moscas de cada concentração, e os resultados dessa análise foram agrupados na Tabela 1.

Tabela 1 - Frequência de clones de tumor observados em Drosophila melanogaster, heterozigota para o gene supressor de tumor wts, tratada com diferentes concentrações do óleo essencial do limão Taiti, isoladas ou associadas ao quimioterápico doxorrubicina (DXR 0,4 mM).

\begin{tabular}{|c|c|c|c|c|c|c|c|c|c|c|c|}
\hline \multicolumn{3}{|c|}{ Tratamentos } & \multirow[b]{2}{*}{$\begin{array}{c}\text { Número } \\
\text { de moscas } \\
\text { analisadas }\end{array}$} & \multicolumn{7}{|c|}{ Número de tumores analisados } & \multirow[b]{2}{*}{$\begin{array}{c}\text { Frequência (№ } \\
\text { de tumores/ } \\
\text { mosca) }\end{array}$} \\
\hline $\begin{array}{l}\text { Limão } \\
\text { Taiti } \\
(\mu \mathrm{L})\end{array}$ & $\begin{array}{c}\text { DXR } \\
(\mathrm{mM})\end{array}$ & $\begin{array}{c}\text { Tween } \\
80\end{array}$ & & Olho & Cabeça & Asa & Corpo & Perna & Halteres & Total & \\
\hline 0 & 0 & $1 \%$ & 150 & 0 & 5 & 2 & 3 & 0 & 0 & 10 & 0,07 \\
\hline 0 & 0 & 0 & 150 & 0 & 6 & 2 & 5 & 0 & 0 & 13 & 0,09 \\
\hline 0 & 0,4 & 0 & 150 & 50 & 237 & 638 & 542 & 778 & 104 & 2349 & $15,66 *$ \\
\hline 1,5 & 0 & 0 & 150 & 2 & 3 & 3 & 5 & 1 & 0 & 14 & 0,09 \\
\hline 3,0 & 0 & 0 & 150 & 0 & 3 & 5 & 3 & 0 & 0 & 11 & 0,07 \\
\hline 6,0 & 0 & 0 & 150 & 3 & 6 & 4 & 1 & 1 & 0 & 15 & 0,1 \\
\hline 1,5 & 0,4 & 0 & 150 & 0 & 5 & 7 & 9 & 1 & 0 & 22 & $0,15 * *$ \\
\hline 3,0 & 0,4 & 0 & 150 & 0 & 8 & 2 & 11 & 3 & 0 & 24 & $0,16^{* *}$ \\
\hline 6,0 & 0,4 & 0 & 150 & 0 & 7 & 6 & 13 & 3 & 0 & 29 & $0,19 * *$ \\
\hline
\end{tabular}




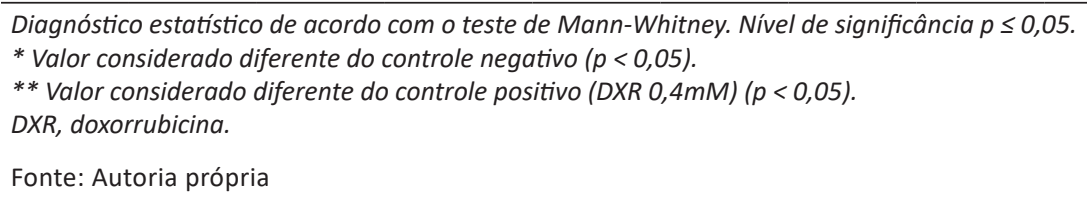

Conforme apresentado na Tabela 1, o controle negativo utilizado no experimento foi tween 80 a $1 \%$. Para confirmar que o Tween $801 \%$ não influenciaria os resultados da pesquisa, foi feito um controle usando água de osmose reversa e ao compará-los é possível notar que não houve diferença estatisticamente significativas entre ambos. Contudo, ao comparar a frequência de tumores $(15,66)$ encontrada no controle positivo (DXR 0,4 mM) com o controle negativo (Tween $801 \%$ ), verifica-se uma diferença estatisticamente significativa $(p<0,05)$, indicando que DXR é um indutor de tumor.

A Tabela 1, também apresenta a frequência de tumores encontrados nos diferentes segmentos do corpo das D. melanogaster tratadas com concentrações isoladas do óleo essencial do limão Taiti $(1,5 ; 3,0 ; 6,0 \mu \mathrm{L})$. Os resultados dessa análise mostram que as frequências de tumores encontradas nestas concentrações não apresentaram resultado significativo $(p>0,05)$ quando comparadas ao controle negativo, evidenciando ausência de efeito carcinogênico.

Já os resultados dos indivíduos tratados com concentrações do óleo essencial do limão Taiti associadas a DXR (Tabela 1) é possível observar uma redução significativa na frequência de tumores $(p<0,05)$, quando comparadas ao controle positivo $(15,66$ tumores por mosca). Essa redução na frequência de tumores pode ser observada nas três concentrações testadas $(0,15$ tumores em $1,5 \mu \mathrm{L}, 0,16$ tumores em $3,0 \mu \mathrm{L}$ e 0,19 tumores em $6,0 \mu \mathrm{L}$ ), indicando efeito modulador do óleo essencial do limão Taiti, capaz de reduzir os danos induzidos pela DXR.

\section{DISCUSSÃO}

O solvente utilizado na diluição do óleo essencial do limão Taiti foi o Tween 80 na concentração de 1\%, mesmo sendo uma substância química, na concentração utilizada não é capaz de causar alterações no experimento, visto que as frequências de tumores entre Tween e água não foram significativas. Esse resultado corrobora com os resultados de Silva (2016), que ao testar a toxicidade de diferentes solventes e surfactantes em Musca domestica L., da mesma ordem da $D$. melanogaster, o autor verificou que o surfactante Tween 80 , quando utilizado em concentrações menores que 5\% não é capaz de influenciar os resultados. Deste modo, a concentração do Tween 80 utilizada neste estudo foi segura. Em adição, é possível notar que as três concentrações testadas do óleo essencial do limão Taiti apresentaram frequências de tumores muito próximas aos valores do controle negativo, evidenciando, ausência de efeito carcinogênico.
Neste contexto, Fonseca (2008) desenvolveu um trabalho que avaliava potencial toxicogenético e quimioprotetor do óleo essencial das cascas de Citrus aurantium L. in vivo. O autor aplicou o teste do micronúcleo em reticulócitos de roedores e verificou a ausência de efeito nos três níveis de doses avaliadas, inclusive na dose terapêutica eficaz nos modelos de avaliação de atividade gastroprotetora. De acordo com autor, a ausência de mutagenicidade se deve ao fato de que o óleo essencial usado tem como predomínio o limoneno, um composto terpênico. $O$ autor aplicou, também, o teste do cometa sobre o DNA de células da mucosa gástrica de roedores, capaz de detectar baixos níveis de toxicidade de compostos em diferentes tecidos. Os resultados do teste cometa revelaram que concentrações menores que $2500 \mathrm{mg} / \mathrm{kg}$ do composto testado não apresentaram efeito genotóxico. Logo, a ausência de mutagenicidade e genotoxicidade de óleo essencial dos Citrus, pode justificar a ausência de efeito carcinogênico na presente pesquisa.

Em relação ao controle positivo, foi utilizado o quimioterápico DXR devido a sua ação indutora tumoral comprovada por outras pesquisas que também utilizaram a Drosophila como organismo teste (ORSOLIN; NEPOMUCENO, 2015; MACHADO; NEPOMUCENO, 2010). Para Alves e Nepomuceno (2012) a doxorrubicina, classificada como potente antineoplásico, tem como função modificar o DNA das células neoplásicas, consequentemente, células saudáveis também sofrem alterações, assim dependendo da concentração e da intensidade das alterações, a DXR pode induzir a formação de tumores.

Diante do efeito de indução tumoral da DXR, diferentes concentrações do óleo essencial do limão Taiti foram associadas ao quimioterápico. E os resultados dessa associação comprovaram que o limão Taiti possui efeito modulador, capaz de modificar a resposta da DXR reduzindo seus efeitos. Portanto, este óleo essencial, nas presentes condições experimentais, apresentou ação anticarcinogênica, eficiente na redução da frequência de tumores induzidos pela DXR. E de maneira discreta, se vê que à medida que as concentrações foram aumentadas, a presença dos tumores diminuiu, revelando a importância das concentrações usadas para a inibição dos tumores.

Os óleos essenciais de frutas cítricas são compostos ricos em hidrocarbonetos, compostos oxigenados e não-voláteis, incluindo terpenos, sesquiterpenos, aldeídos, álcoois, ésteres e esteróis. (BEN HSOUNA et al., 2017). Estes compostos presentes nos cítricos podem agir como redutores, interruptores de radicais livres, inibidores ou supressores de oxigênio e inativadores de metais pró-oxidantes (LUZIA; JORGE, 2010). Este pode ter sido um 
dos mecanismos pelos quais houve redução na frequência de tumores, visto que a DXR é um potente gerador de radicais livres, pois a mesma inibiu a topoisomerase II, uma enzima de grande relevância no processo de replicação do DNA. E em função de seu grupo quinona, geram radicais livres em tecidos normais e malignos (MOURA, 2011).

Para Maróstica Júnior (2006), o limoneno apresenta evidente efeito quimiopreventivo durante a fase inicial de carcinomas induzidos em ratos com 7-12-dimetilbenzo-antraceno (DMBA) e durante a fase de indução de carcinomas com DMBA e nitrosometiluréia (NMU). O limoneno e álcool perílico presente no óleo essencial mostrou possuir atividade quimioterapêutica contra câncer de mama em ratos, por provocar completa regressão dos carcinomas induzidos por DMBA ou NMU. Os ratos utilizados na pesquisa foram alimentados com $5 \%$ de limoneno em sua dieta por duas semanas, o composto se mostrou capaz de reduzir a interação do carcinógeno com o DNA do animal.

De acordo com Gharagozloo et al. (2002) relata os efeitos in vitro do uso dos flavonoides presentes no extrato de Citrus aurantifolia, em que inibiu de forma espontânea a proliferação de células de linhagem RPMI8866, mas não a célula MDA-MB-453. Estes flavonóides cítricos são inibidores efetivos de receptor de estrogênio MDA-MB-453 negativo e estrogênio que são linhagens de células de câncer mamário em humanos e MCF-7 positivas para o receptor. $\mathrm{O}$ autor ainda propõe que o extrato do composto tem ação antiproliferativa, ou seja, tem efeito imunomoduladores sobre linfócitos humanos ativados.

Rozza (2011) evidencia a ação do limoneno no óleo essencial do Citrus lemon com uma eficácia gastroprotetora contra úlceras induzidas por etanol, esta atividade se deve ao ativar a proteína heat-shock e liberar peptídeos intestinais vasoativos, mas esta não pode ser o único mecanismo, pode estar relacionada com um conjunto de mecanismos gastroprotetor. Outro ponto abordado pela autora, foi as úlceras causadas por uso de Anti-inflamatórios não-esteroides (AINES), que inibi a ciclooxigenase (COX), e como reação adversa à diminuição da $\mathrm{PGE}_{2}$, uma prostaglandina que protege naturalmente o estômago de ulcerações, quando utilizado o AINE com o óleo essencial em estudo, foi observado que o nível de $\mathrm{PGE}_{2}$ continuou elevado, comprovando um efeito gastroprotetor por manter os níveis aumentados desta prostaglandina.

Stark et al. (1995) diz que o álcool perílico presente no óleo essencial de cítricos tem ação quimiopreventiva contra o câncer de fígado em ratos e em cultivos de células humanas com carcinoma de cólon, inibiu a proliferação das células cancerosas. $O$ autor mostra com um estudo feito com células pancreáticas neoplásicas de hamster, foi analisado que este álcool quando administrados no roedor por via oral e dose dependente, observou uma redução considerável no crescimento de tumores PC-1, este, um dos mais agressivos tumores usado como controle.

\section{CONCLUSÃO}

O teste para deteç̧ão de tumores epiteliais em Drosophila melanogaster, na presente condição experimental, permite concluir que o óleo essencial do limão taiti não apresentou efeito carcinogênico, mas sim ação anticarcinogênica, pois foi capaz de reduzir os danos induzidos pela DXR. O efeito anticarcinogênico pode estar relacionado com a presença de substâncias químicas contidas no óleo essencial do limão Taiti como monoterpenos, sesquiterpenos, aldeídos, álcoois, os quais possuem ação antioxidante.

Pesquisas com outros organismos modelo e novas metodologias, seriam de grande valia para elucidar os reais benefícios do óleo essencial do limão Taiti na carcinogênese, com a finalidade de contribuir para uma melhora na qualidade de vida e benefícios para a saúde.

\section{REFERÊNCIAS}

ALVES, E. M.; NEPOMUCENO, J. C. Avaliação do efeito anticarcinogênico do látex do avelós (Euphorbia tirucalli), por meio do teste para detecção de clones de tumor (warts) em Drosophila melanogaster. Perquirere, Minas Gerais, v. 9, n. 2, p.125-140, 2012. Disponível em: http:// perquirere.unipam.edu.br/documents/23456/57344/avaliacao-doefeito-anticarcinogenico.pdf. Acesso em: 27 jan. 2018.

BEN HSOUNA, A. et al. Citrus lemon essential oil: chemical composition, antioxidant and antimicrobial activities with its preservative effect against Listeria monocytogenes inoculated in minced beef meat. Lipids healt dis., London, v.16, n.146, p. 2-11, 2017. Disponível em: https:// lipidworld.biomedcentral.com/track/pdf/10.1186/s12944-017-04875?site=lipidworld.biomedcentral.com. Acesso em: 27 jan. 2018.

COELHO, Y. S. Lima ácida 'Taiti' para exportação: aspectos técnicos da produção. Ministério da Agricultura do Abastecimento e da Reforma Agrária. Brasília: EMBRAPA-SPI, 1993. p.35. Disponível em: < file:///C:/ Users/Bruna/Downloads/Lima-aida-tahiti-exportacao-aspecto-tec.pdf> Acesso em: 17 out. 2016.

DAHER, C. F.; BAROODY, G. M.; HOWLAND, R. J. Effect of a surfactant, Tween 80, on the formation and secretion of chylomicrons in the rat. Food and Chemical Toxicology, v. 41, p. 575-582, 2003. Disponível em: < https://sci-hub.tw/10.1016/s0278-6915(02)00299-5> Acesso em: 17 out. 2016 .

EDRIS, A. E. Pharmaceutical and therapeutic potentials of essential oils and their individual volatile constituents: a review. Phytother. Res., London, v. 21, n. 4, p. 308-323, 2007. Disponível em: https://sci-hub. tw/10.1002/ptr.2072. Acesso em: 14 nov. 2016.

FENG, J. et al. The Surfactant Tween 80 Enhances Biodesulfurization. Applied and environmental microbiology., p. 7390-7393, 2006. Disponível em: https://sci-hub.tw/10.1128/AEM.01474-06. Acesso em: 14 nov. 2016

FIGUEIREDO, C. Aplicação de plantas aromáticas e óleos essenciais encapsulados em produtos lácteos. 2010. 79f. Relatório de Estágio (Especialização Tecnológica em Qualidade Alimentar) - Instituto Politécnico de Coimbra, Escola Superior Agrária, Coimbra, 2010. 
Disponível em:<http://www.esac.pt/noronha/coordenadorCETQA/ relatorios/RELATORIO\%20DE\%20ESTAGIO\%20-\%20CRISTIANA\%20 FIGUEIREDO\%2020853002.pdf>Acesso em: 17 out. 2016.

FONSECA, V. B. Avaliação do potencial toxicogenético e quimioprotetor do óleo essencial das cascas de Citrus aurantium L. in vivo. 2008. Tese (Mestrado) - Instituto de Biociências de Botucatu da Universidade Estadual Paulista (UNESP), São Paulo, 2008. Disponível em: <http:// www.ibb.unesp.br/posgrad/teses/farmacologia_2008_vitor_fonseca. pdf> Acesso em: 27 jan. 2018.

GHARAGOZLOO, M. et al. Effects of Citrus aurantifolia concentrated extract on the spontaneous proliferation of MDA-MB-453 and RPMI8866 tumor cell lines. Phytomedicine, v. 9, n. 5, p. 475-477, 2002. Acesso em: < https://sci-hub.tw/> Acesso em: 27 jan. 2018.

GRASSI FILHO, H. et al. Preparo de amostras e métodos para a determinação do teor de óleo essencial de frutos de limoeiro. Rev. Bras. Frutic., Jaboticabal - SP, v. 27, n. 1, p. 191-193, 2005. Disponível em: <http://www.scielo.br/pdf/rbf/v27n1/24601.pdf> Acesso em: 18 out. 2016.

LUZIA, D. M. M.; JORGE, N. Potencial antioxidante de extratos de sementes de limão (Citrus limon). Ciênc. Tecnol. Aliment., Campinas, v. 30, n. 2, p. 489-493, abr./jun. 2010. Disponível em: <http://www.scielo. br/pdf/cta/v30n2/29.pdf> Acesso em: 27 jan. 2018.

MACHADO, N. M.; NEPOMUCENO, J. C. Efeito modulador da vitamina $\mathrm{K}$ contra a ação carcinogênica da doxorrubicina, avaliado por meio do teste para detecção de clones de tumor (warts) em Drosophila melanogaster. Perquirere, Patos de Minas: UNIPAM, v. 1, n. 7, p. 180193, ago. 2010. Disponível em: <http://perquirere.unipam.edu.br/ documents/23456/36602/Efeito_modulador_da_vitamina_k_contra_a_ acao.pdf> Acesso em: 27 jan. 2018.

MARÓSTICA JUNIOR, M. R. Biotransformação de terpenos para a produção de compostos de aroma e funcionais. 2006. 195f. Tese (Doutorado) - Universidade Estadual de Campinas, Faculdade de Engenharia de Alimentos, Campinas SP, 2006. Disponível em: < http:// repositorio.unicamp.br/bitstream/REPOSIP/256710/1/MarosticaJunior_ MarioRoberto_D.pdf> Acesso em: 27 jan. 2018.

MENDONÇA, L. M. V. L. et al. Caracterização da composição química e do rendimento dos resíduos industriais do limão Tahiti (Citrus latifolia Tanaka). Ciênc. Tecnol. Aliment., Campinas, v.26, n. 4, p. 870-874, 2006. Disponível em: < http://www.scielo.br/pdf/cta/v26n4/24.pdf> Acesso em: 14 nov. 2016.
MOURA, L. R. Cardiotoxicidade induzida pela doxorrubicina: mecanismos de lesão e terapias antioxidantes (Revisão da literatura). 2011. Tese (Doutorado) - Universidade Federal de Goiás, Goiânia, 2011. Disponível em: <https://portais.ufg.br/up/67/o/Seminario2011_Lea_ Moura_1c.pdf> Acesso em: 24 set. 2019.

ORSOLIN, P. C.; NEPOMUCENO, J. C. Avaliação do efeito modulador de diferentes estatinas sobre danos ao DNA induzidos pela doxorrubicina em células somáticas de Drosophila melanogaster. 2015. 117f. Tese (Doutorado) - Universidade Federal de Uberlândia, Programa de PósGraduação em Genética e Bioquímica, Uberlândia, 2015. Disponível em: <https://repositorio.ufu.br/bitstream/123456789/15765/1/ AvaliacaoEfeitoModulador.pdf> Acesso em: 27 jan. 2018.

ROZZA, A. L. et al. Gastroprotective mechanisms of Citrus lemon (Rutaceae) essential oil and its majority compounds limonene and - pinene: Involvement of heat-shock protein-70, vasoactive intestinal peptide, glutathione, sulfhydryl compounds, nitric oxide and prostaglandin E2. Chem. Biol. Interact., Amsterdam, n. 189, p. 82-89, 2011. Disponível em: < https://sci-hub.tw/https://doi.org/10.1016/j. cbi.2010.09.031>. Acesso em: 09 jan. 2018.

SILVA, B. C. Avaliação da toxicidade de quatro solventes e um surfactante, e dos fenilpropanoides eugenol e (E)-cinamaldeidosobre larvas epupas de Musca domestica Linnaeus, 1958 (Díptera: Muscidae). 2016. 73 f. Dissertação (Mestrado) - Universidade Federal de Juiz de Fora, Instituto de Ciências biológicas, Minas Gerais, 2016. Disponível em: <http://repositorio.ufjf.br:8080/xmlui/bitstream/handle/ufff/4062/ biancacarvalhodasilva. pdf? sequence $=1$ \&isAllowed $=y>$ Acesso em: 09 jan. 2018.

SILVEIRA, P. F. et al. Farmacovigilância e reações adversas às plantas medicinais e fitoterápicas: uma realidade. Rev. Bras. Farmacogn., São Paulo, v.18, n.4, p. 618-626, 2008. Disponível em: <http://www.scielo. br/pdf/rbfar/v18n4/v18n4a21.pdf >Acesso em: 14 nov. 2016.

SPADACIO, C.; BARROS, N. F. Uso de medicinas alternativas e complementares por pacientes com câncer: revisão sistemática. Rev. Saúde Pública, São Paulo, v. 42, n.1, p.7-13, 2008. Disponível em: < http://www.scielo.br/pdf/rsp/v42n1/6114.pdf> Acesso em: 14 nov. 2016.

SPADACIO, C. et al. Medicinas Alternativas e Complementares: uma metassíntese. Cad. Saúde Pública, Rio de Janeiro, v. 26, n.1, p.7-13, 2010. Disponível em: < http://www.scielo.br/pdf/csp/v26n1/02.pdf> Acesso em: 14 nov. 2016.

STARK, M. J. et al. Chemotherapy of pancreatic cancer with the monoterpene perillyl alcohol. Cancer Lett., Virgínia,v. 96, p. 15-21, 1995. Disponivel em: <https://sci-hub.tw/https://doi.org/10.1016/03043835(95)03912-G> Acesso em: 27 jan. 2018.

Submetido em: 23/07/2018

Aceito em: 06/01/2020 